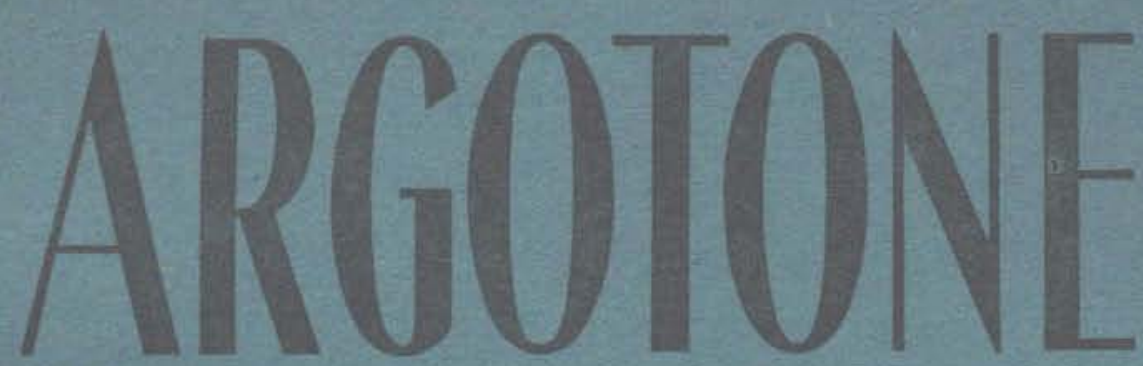

\title{
NASAL DROPS
}

A Medical Preparation for NASAL, THROAT and EYE AFFECTIONS

The main components of ARGOTONE are ARGYROL \& NATURAL EPHEDRINE made into a stable combination by a special process.

ARGOTONE is only used on Prescription and MEDICAL RECOMMENDATION and no Advertising is ever made to the Public.

\section{RONA LABORATORIES LTD LONDON 99 OAKLANDS ROAD N.W. 2}




\section{AN \\ EMERGENCY BRONCHOSCOPE}

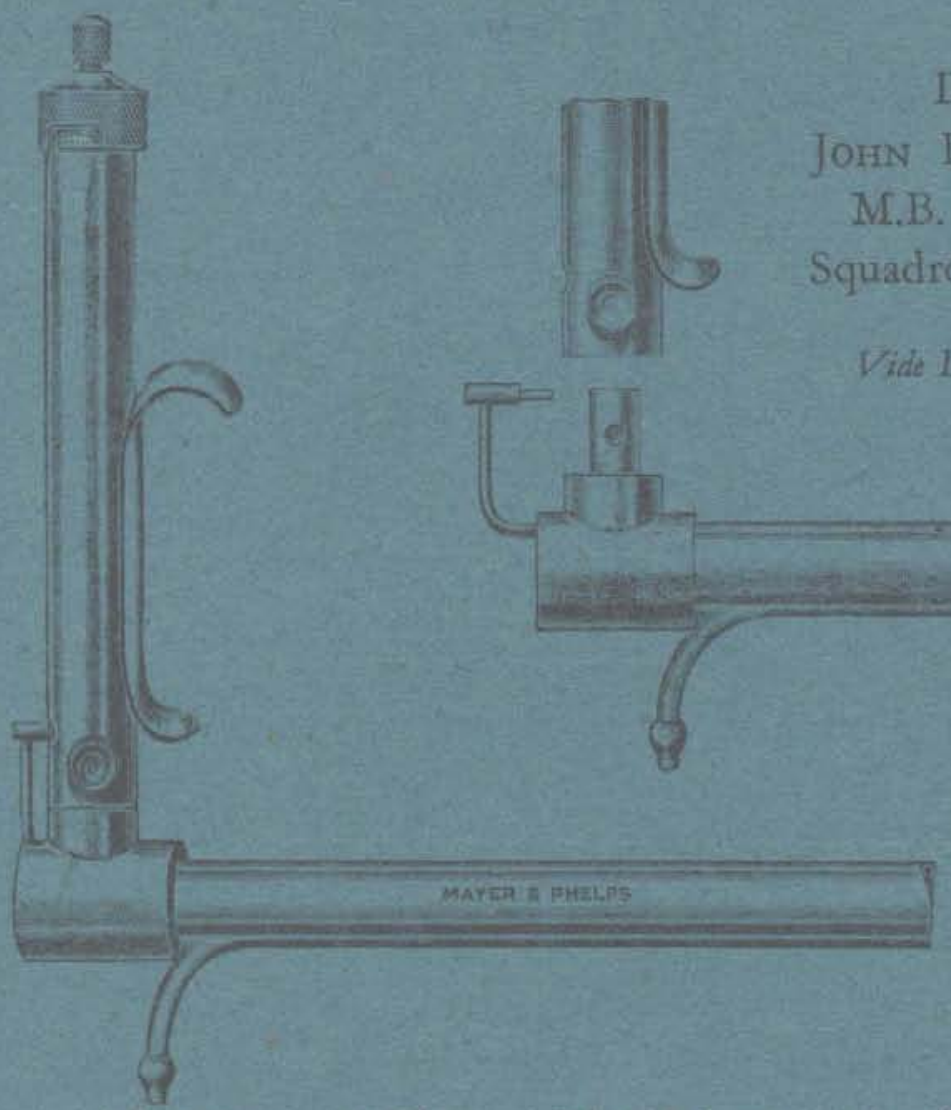

Designed by JOHN E. G. MCGIBBON, M.B. (Lond.), D.L.O. squadron-Leader, A.A.F.

Vide Lancet July 26,1941

A Bronchoscope self contained with battery in handie, dispensing with entangling cables.

The Bronchoscope was designed for Bronchial aspiration and insufflation of oxygen in cases of emergency.

The handle is provided with a finger rest to facilitate introduction, and is detachable for sterilization.

Gssophagoscopes and Bronchoscopes can be made of various lengths and calibres as desired (see page 73 , Catalogue of Laryngology). That illustrated above is $40 \mathrm{~cm}$. $\times 10 \mathrm{~mm}$.

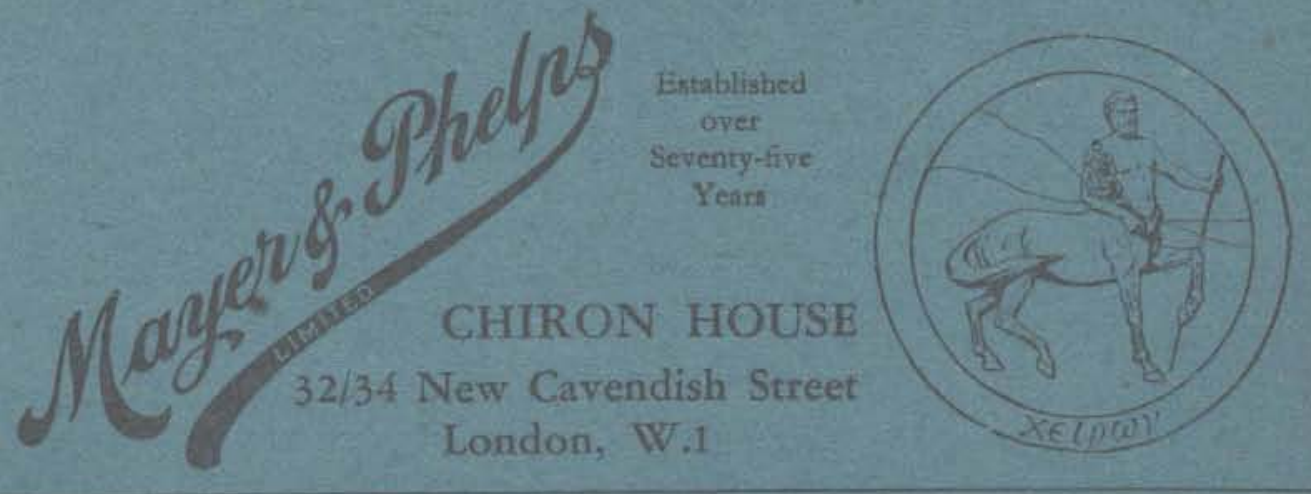

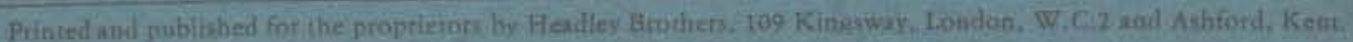
https://doi.org/10.1017/S0022215100011348 Published online by Cambridge University Press 